\title{
Zola e Gonzaga Duque: o artista e a cidade na virada do século
}

\author{
Vera Lins*
}

\begin{abstract}
Resumo
O objetivo desse ensaio é ler comparativamente o mundo das artes e a cidade no final século XIX e início do XX em dois romances, L'Oeuvre, de Émile Zola, e Mocidade Morta, de Gonzaga Duque, mostrando seus pontos de contato e suas especificidades.
\end{abstract}

Palavras-chave

Gonzaga Duque. Zola. Artista. Cidade.

A discussão sobre a cidade aqui é mais pano de fundo para uma discussão sobre a arte, a pintura, num romance de Zola e num romance de Gonzaga Duque. Zola publicou o romance L'Oeuvre em 1886 e Gonzaga Duque, o romance Mocidade morta em 1899. Ambos são narrativas que tratam do meio das artes. Gonzaga Duque foi crítico de artes plásticas e romancista na virada do século, nasceu no Rio de Janeiro em 1863 e morreu em 1911. Publicou $A$ arte brasileira, Graves e frívolos, vários artigos na imprensa da época e, além do romance Mocidade morta, um livro de contos e um de história, em que narra movimentos revolucionários brasileiros que não constam dos livros oficiais.

Seu romance se passa no Rio de Janeiro de 1887, dois anos antes da proclamação da república brasileira, e narra as tentativas de um crítico de artes plásticas, duplo seu, de organizar um grupo de pintores, Os Insubmissos, que, rebeldes à arte acadêmica, trariam a nova arte do plein air às terras cariocas.

Leitor da literatura francesa, Gonzaga Duque mencionava Zola em seus textos de crítica de artes plásticas. Mas as pistas para as afinidades entre os dois romances são dadas pelo próprio autor brasileiro. No começo de Mocidade morta, Gonzaga Duque $(1995$, p. 37$)$ se refere a L'oeuvre e cita do seu jeito a frase de Sandoz que termina o romance francês, Allons travailler: "A imposição dependia da perseverança, o que já estava definido numa frase final da Oeuvre, que saiu da boca de Sandoz: Allons nous en travailler." Mais no final da narrativa (p. 227), compara, explicitamente, Camilo Prado a Claude Lantier, o pintor, herói do romance francês.

\footnotetext{
* Doutora em Literatura pela UFRJ, onde leciona Literatura Comparada, especialmente os seguintes temas: Gonzaga Duque, simbolismo, poesia, Rio de Janeiro e crítica.
} 
Fizera-se a peste, contagiou a alma sã dessa gente com a febre inquietadora da sua doença de espírito - uma nebulosa instrução supercoeva do que estava para vir - a antevidência desse atormentado Moderno que vai, num deslumbramento de demência, seduzindo os Cláudios Lantiers da Nova Era.

Zola em carta diz que é sua juventude que conta no romance: "C'est toute ma jeunesse que je raconte, j'ai mis là tous mes amis, je m'y suis mis moi-même. Je veux surtout étudier comment pousse l'oeuvre d'art, et j'ai un drame de passion au travers du livre, qui interessera, je crois" (ZOLA, 1974). ${ }^{1}$ O personagem Sandoz, escritor companheiro do pintor Lantier, tem momentos em que faz uma defesa do naturalismo na literatura como num grito que termina com a frase "Oui, on verra la littérature qui va germer pour le prochain siècle de science et de démocratie!" (p. 219) Nessa passagem traça o projeto de Zola com os Rougon-Macquart:

[...] Je vais prendre une famille, et j'em étudierai les membres, un à un, d'oú ils viennent, où ils vont, comment ils réagissent les uns sur les autres; enfin, une humanité em petit, la façon dont l'humanité pousse et se comporte... [...]

Sandoz fala páginas seguidas sobre seu trabalho de escritor, o que the custa de tormento e desespero.

O escritor brasileiro também rememora sua juventude, ficcionalizada no romance, o que se pode comprovar por seu diário e pelos artigos e crônicas que publicou. Mas é da modernidade e do embate no espírito do artista entre habilidade e gênio, recuperando a idéia de gênio do romantismo alemão ou de Baudelaire como a define no artigo, "Salão de 1859", de que ambos tratam. Para o poeta e crítico francês há uma habilidade que se pode adquirir pela paciência que faz os artistas acadêmicos a quem falta imaginação. No entanto a imaginação também requer o domínio do ofício para sustentá-la em suas aventuras e superar as dificuldades que ela busca avidamente. Ambos os personagens não são impotentes, mas criadores de ambição muito ampla querendo colocar toda sua natureza numa obra. Zola declara que produzia sabendo que a obra é imperfeita e se submetendo a isso com grande tristeza (p. 51). Os pintores no romance exclamam "Quelle place à prendre! Dompter la foule, ouvrir um siècle, créer un art!" (p. 254). Com esse desejo enfrentam dificuldades às vezes insuperáveis.

Camilo Prado, o crítico-romancista de Mocidade morta diz: "Nós precisamos de termos novos como de novas sensações. Há quase cem anos que consumimos os legados literários da língua. Estão exaustos esses acervos". O desejo de ver e experimentar sensações novas diante da banalização e da trivialidade está também em Claude Lantier, a mesma melancolia, o confronto com as experiências de choque na rua e a luta contra a imbecilidade burguesa. Claude afirma "- Ah! tout voir et tout peindre" (p. 102). Em Zola o herói é duplo, o escritor e o pintor, que se exaltam nas discussões em que partilham a paixão pelo trabalho e os sonhos de glória (p. 103):

\footnotetext{
${ }^{1}$ Citado na introdução do romance por Antoinette Ehrard.
} 
Dès qu'ils étaient ensemble, le peintre et l'écrivain en arrivaient d'ordinaire à cette exaltation. Ils se fouettaient mutuellement, ils s'affolaient de gloire; et il y avait là une telle envolée de jeunesse, une telle passion du travail, qu'eux-mêmes souriaient ensuite de ces grands rêves d'orgueil, regaillardis, comme entretenus en souplesse et en force.

O escritor Sandoz e o pintor Lantier são duas faces do artista. Em ambos os romances os encontros dos artistas provocam discussões sobre arte e a sociedade em que vivem com personagens que encorpam atitudes diversas. Claude Lantier é o angustiado chefe da escola do plein air em quem os companheiros depositam suas esperanças:

Et ils se rabattirent sur Claude, ils se prosternèrent, l'accablèrent des espérances qu'ils mettaient em lui. Ah! il était temps qu'il revînt, car lui seul, avec ses dons de grand peintre, as poigne solide, pouvait être le maître, le chef reconnu! (p. 254).

Claude procura uma pintura nova, outra, que, no entanto, não sabe ainda o que é, mas a defende entusiasmado no início da narrativa, em conversa com Sandoz e o grupo:

\begin{abstract}
- Maintenant, il faut autre chose... Ah! quoi? Je ne sais pas au juste! Si je savais et si je pouvais, je serais très fort. Oui, il n'y aurait plus que moi... Mais ce que je sens, c'est que le grand décor romantique de Delacroix craque et s'effondre; et c'est encore que la peinture noire de Courbet empoisonne déjà le renfermé, le moisi de l'atelier où le soleil n'entre jamais... Comprends-tu, il faut peut-être le soleil, il faut le plein air, une peinture claire et jeune, les choses et les êtres tels qu'ils se comportent dans la vraie lumière, enfin je ne puis pas dire, moi! Notre peinture à nous, la peinture que nos yeux d'aujourd'hui doivent faire et regarder (p. 101).
\end{abstract}

Mas as fissuras no grupo aparecem rápido:

Alors, Claude sentit nettement quelque chose se rompre. La vie avait-elle donc emporté déjà les soirées d'autrefois, si fraternelles dans leur violence, où rien ne les séparait encore, où pas um déux ne réservai as part de gloire? Aujourd'hui la bataille commençait, chaque affamé donnait son coup de dents. La fissure était là, la gente à peine visible, qui avait fêlé les vieilles amitiés jurées, et qui devait les faire craquer un jour, em mille pièces (p. 255-256).

Em L'oeuvre aparecem dois marchands, o père Maugras, um conaisseur que salva os artistas, comprando suas telas e Naudet, um especulador, um explorador da pintura, que vai lançar Fagerolles, o pintor que roubava o talento do amigo, Lantier:

Il apportait l'unique flair du succès, il devinait l'artista à lancer, non pas celui que promettait le génie discuté d'um grand peintre, mais celui dont le talent menteur, enflé de fausses hardiesses, allait faire prime sur le marché bourgeois (p. 243).

Jory é o crítico que tem seus artigos nos jornais cortados quando fala dos seus amigos, e sonha com um jornal próprio: "- Dame! mon cher, répondit Jory vexé, tout ce que j'écris pour vous, on me le coupe. Vous vous faites exécrer partout... Ah! si j'avais um journal à moi!" (p. 255). 
Em Mocidade morta, o crítico de artes se desdobra em romancista. O pintor Agrário, o mais promissor do grupo, vai ser bem sucedido, viaja a Paris e sugere-se que voltará para ser como o pintor acadêmico que abre a narrativa com a exposição de sua tela de batalha. É referido como o original Agrário, o rebelde Agrário, o alegre, falador, irrequieto Manet indígena. Assemelha-se a Fagerolles, o pintor do romance francês que, ao contrário de Lantier, obtém sucesso, aproveitando as idéias do amigo, adaptando-as com habilidade ao gosto do público. No final, Fagerolles faz parte do júri do Salão e influi para que aceitem um quadro de Lantier, mas isso quando a pintura clara, "en plein air", que fazia o pintor genial, já estava sendo admitida e copiada por muitos.

A escolha de um crítico de arte para personagem principal de Mocidade morta revela uma concepção interessante de crítica como invenção, crítica producente pela orientação e pelo estímulo. Retoma-se a idéia de crítica do idealismo alemão. Crítica não é julgamento, mas arte e reflexão potenciada sobre a arte. Não há distinção entre juízo estético e criação. Na crítica filosófica o saber artístico toma consciência de si e se reveste de uma nova figura. A crítica desperta a faculdade de criar. O crítico Camilo Prado quer realizar a transformação da maneira de pensar. Discorre sobre o impressionismo, a crítica de Zola e Huysmans, Féneon e Ramalho Ortigão. Sonha com a revolução artística, a fundação de ateliês livres e exposições independentes. Para ele, a situação da arte brasileira era desesperadora e assim fala ao grupo de pintores:

\begin{abstract}
A arte de pintar está parada neste país, enfezou nos cueiros. Enquanto ela na Europa serve de uma técnica vigorosa que possui todos os segredos da refração da luz, do prisma solar; todos os recursos da química, que lhe dão a transparência das tintas, a segurança dos valores, a límpida simplicidade dos tons, aqui continua nos arcaicos processos onânicos da pintura friccionada, esbatida e raquítica, sem nervos, sem sangue, sem alma. É uma masturbação à blaireau. E o que pode resultar deste vício secreto senão a clorose desanimadora, o contágio desmoralizador que estamos observando? Vocês vivem na Academia, como se vivessem num internato de padralhões sórdidos, sob o jugo da rotina e a infecção do sodomismo, bestializam-se e esgotam-se. Para cada parede que olham, em cada passo que fazem, têm o mau exemplo, uma arte sem valor técnico e sem espiritualidade. A Pinacoteca ali está, reparem em suas coleções. Que pobreza! Que impotência! Não se nota na maioria dessas obras uma alma, um temperamento (GONZAGA DUQUE, 1995, p. 38).
\end{abstract}

Pretende uma dissidência, um rompimento, uma secessão:

Combinando, agremiando, poderíamos formar uma oposição vitoriosa, fundaríamos ateliers livres, teríamos exposições independentes, em suma, seríamos uma corporação vivendo vida própria, exercendo uma profissão (p. 45).

Em toda a sua crítica de artes plásticas Gonzaga Duque defende uma pintura clara que traga nas telas a luz dos trópicos e conta em artigos como "O aranheiro da escola", recolhido no livro Contemporâneos, sobre a tentativa de um grupo de artistas de se organizarem em ateliês livres com a proclamação da República. Também num artigo da revista Kosmos "O cabaré de Ivonne", conta de jovens boêmios, republicanos radicais que sonhavam com Paris. No romance, o crítico expressa esse desejo de articulação, logo no início, num encontro numa taberna em que o grupo de pintores se reúne: 
O pintor piscou, significativamente, para Camilo, mas ele fixava o espaço, absorvido, concentrado num grande sonho; - Se lhe fosse dado formar um grupo de obscuros e de convictos, uma limitada boêmia de afinados, vivendo todos para o culto religioso de sua Arte!... (p. 56).

Efetivamente no romance se forma um grupo de rebeldes e apaixonados contra o burguês subserviente e comum, a podre academia e a infame sociedade, mas logo ou se deixam cooptar ou param de trabalhar e se dispersam

Em ambos os romances perpassa a idéia de gênio kantiana e própria do romantismo: o próprio inventor muitas vezes é incapaz de perceber onde reside a própria originalidade (produto de ousadia e audácia) daquilo que pela primeira vez formula. A genialidade residiria na faculdade de apreender o jogo rapidamente transitório da imaginação e unificá-lo em um conceito que se deixa comunicar sem a coação de regras. $O$ gênio permite exprimir o indizível de um estado da mente. $E$ ainda não faz uma obra, mas é a obra ou a obra é ele próprio se fazendo. ${ }^{2}$

Mas, embora similares no assunto, os dois romances são narrativas diferentes. No de Gonzaga Duque, a narrativa é problematizada. Se a arte nova, o plein air é algo ainda difícil de ser realizado e a república ainda é sonho, a forma se debate com a impossibilidade. Subverte-se a linearidade do enredo e da frase. Aqui se tenta ampliar a experiência pelo novo na própria palavra com neologismos e expressões raras.

Não há mais a distância estética que torna o romance uma ficção fechada como um palco italiano como acontece em L'oeuvre. Em Mocidade morta, as partes são soltas, há poemas em prosa que se encaixam em quadros naturalistas. A ação é rarefeita, o narrador se problematiza, o romance ganha em reflexão e exige um leitor ativo que acompanhe as longas explanações sobre arte, que o levam perto do ensaio. Há ainda um romance dentro do romance - o crítico lê para os amigos partes do romance que está escrevendo. Gonzaga Duque construiu longos monólogos em discurso indireto livre. Embora defendendo uma arte impressionista no romance, Gonzaga Duque se liga ao grupo simbolista carioca que se fundou em torno da revista Folha popular, que contava com o poeta Cruz e Souza e o crítico Nestor Victor, entre outros. Há uma clara intenção de discutir idéias, em vários momentos o tom é ensaístico. Romance, autobiografia e ensaio tensionam, por isso o romance completa a crítica de arte de Gonzaga Duque.

Nele o desejo de arte nova é também desejo de uma nova sociedade e de uma nova cidade. Mas Gonzaga Duque parece partilhar com Zola o determinismo. Camilo, o personagem principal tem uma história familiar complicada com pai que se suicidou e fica claro que não vai se desvencilhar da situação. No entanto a dissolução no final do romance não é só do crítico, mas de todo o grupo, com exceção do pintor Agrário, que parte para a Europa. Com isso parece dizer que a modernidade é mais atroz nos trópicos, com uma imbecilidade burguesa mais terrível, com perdas e danos mais dolorosos. Há cenas extremamente irônicas: um pintor divide o quadro em dois para fazer um bom negócio.

\footnotetext{
${ }^{2}$ Ver Suzuki (1998).
} 
No romance brasileiro o personagem central também é flâneur, sai de ateliê em ateliê, cruza a cidade do Rio como Claude Lantier cruza Paris. L'oeuvre abre com o artista na rua.

Claude passait devant I"Hotel de Ville, et deux heures du matin sonnaient à I'horloge, quand l'orage éclatat. Il s'était oublié à rôder dans les Halles, par cette nuit brûlante de juillet, em artiste flâneur, amoureux du Paris nocturne (p. 67).

Ambos precisam do plein air das ruas. Camilo vê a cidade como uma pochade impressionista. Assim se refere à rua do Ouvidor, centro chique da época:

Caía a hora bizarra. A rua acanhada e feia, na sua diurna agitação de preferida, tinha o aspecto variegado e promíscuo de uma pochade impressionista de feira, em domingo. O rumor dos cafés onde filarmônicas esganiçava pelas requintas e violinos, a parlenda das calçadas, reverberavam no ar toldado e verânico, pesado de luz, insuportável pelo rumorejo meridional dessa estreiteza desleixada de vala, num formilhar contínuo (GONZAGA DUQUE. 1985, p. 51).

Várias vezes aparece o centro boêmio da cidade nos encontros dos artistas com o crítico. A revolução que ele quer fazer se daria nas ruas, em plein air? O romance abre com a exposição do pintor consagrado pela Academia e pela monarquia. Diante de seu quadro histórico monumental, as relações e idéias se mostram pelos comentários feitos. O grupo dos Insubmissos está presente para desafiar a pintura e o pintor em campo aberto.

Percorre-se a cidade, da rua do Ouvidor aos arrabaldes pobres, com o crítico flâneur, "nervos tensos feito um herói? A discutir com minha alma tão cansada" como no poema de Baudelaire, "Os sete velhos" (BAUDELAIRE, 1985, p. 331). No Rio como na Paris do segundo Império francês, a rua tanto pode ser lugar de uma "corrente bravia" quanto propiciar encontros fugazes, como na cena em que o atrai uma desconhecida no bonde. Não chegam a se falar, sentados juntos, a sensualidade os impele a se tocarem, mas rápido a multidão os separa. Baudelaire é referência neste quadro. Camilo Prado diz que Baudelaire é seu poeta, não os românticos nacionais, Gonçalves Dias e Castro Alves (GONZAGA DUQUE, 1985, p. 196). A imaginação, como Baudelaire a concebia, se opõe à outra, à imaginação burguesa, que "não vibra, não é um produto inteligente de nervos apurados", é mais "uma fantasia indolente de opiados" (p. 162).

Numa descrição que vai se estender por duas páginas de novo a rua é comparada a uma feira (p. 209):

Entretanto, estavam no ruído ouvidoriano, à hora efervescente da passagem, às três da tarde. Mas olhavam desatentamente, de olhos esquecidos, essa promiscuidade que fervia por entre os estreitos renques de casarias irregulares, num rumorejante movimento feiral.

As descrições da cidade, em que Zola exercitava uma escrita pintura, se reduzem em Mocidade morta, embora, quando surjam, revelem também um escritor que se quer pintor. Muitas vezes a cidade é vista das janelas, enquadrada. Há várias cenas em que os personagens principais, o crítico, seu amigo pintor e sua amante aparecem à janela, ou em que olham a cidade através de janelas. 
Cabe aqui o que diz Rosalind Krauss (1993, p. 16) sobre a janela na pintura moderna: tanto significa abertura ao infinito de possibilidades, como limite, prisão, enquanto espelho em que o eu se prende. A crítica americana estuda a significação das grids na arte moderna como um modelo para o antinarrativo. E vê nas janelas uma antecipação desse padrão já presente nos românticos e no início do século dezenove, mas que toma uma direção modernista com os simbolistas, quando são experimentadas tanto como transparentes, trazendo luz, espírito à escuridão do quarto ou opacas, como um espelho que congela e prende o eu no espaço do ser reduplicado:

If the window is the matrix of ambi-or multivalence, and the bars of the windows the grid - are what help us to see, to focus on, this matrix, they are themselves the symbol of the simbolist work of art. They function as the multilevel representation through which the work of art can allude, and even reconstitute the forms of Being.

Em vários momentos as janelas param o fluxo narrativo e introduzem ambigüidade numa situação que tanto pode significar liberdade, infinito quanto limite como a relação com a mulher e a cidade. Camilo, desejoso de liberdade, no entanto, tem a ação limitada. É inclusive demitido do jornal em que trabalha por sua atuação rebelde à Academia, que passa a ser dirigida pelo pintor que inaugura sua exposição no início do romance. A janela se torna jaula. Reflete-se sobre o sujeito moderno, cindido. O personagem, por sua integridade, recusa o mundo e é rechaçado por ele. Dividido, faz uma crítica radical da insuficiência do que existe em relação ao que poderia ser. Mas perde-se na autoprospecção, no espelho em que se transforma a janela:

Revolvendo mentalmente os sucessivos episódios deste passado, Camilo sentia a satisfação amarga de compreender-se, de anatomizar o seu próprio ser, nesses retaliamentos de análise.

A narrativa constrói um auto-retrato impiedoso e irônico em que o personagem se aproxima de outros heróis simbolistas Há uma tensão do religioso e metafísico com o estético. Romper com normas é um ato metafísico, aventura de autoconhecimento, experiência intima que se debate com a ação. Através da discussão com tipos que encontra ou que vai visitar, o crítico afirma suas idéias, o que renega e o que defende. Discute com o bacharel, com o pintor positivista, com o doutor que quer ligar arte e ciência, personagens que personificam idéias. A cidade se transforma em arena, e os cafés, em barricadas de onde os artistas boêmios investem.

Nos dois romances a relação com a cidade é uma batalha: conquistar a cidade ou ser subjugado. $\mathrm{Na}$ forma urbana se concretiza um pensamento: o tipo de racionalidade que preside à cidade moderna é excludente e violenta, quer extirpar o conflito e a diferença. A cidade torta e pontilhada de vitrines já é presidida pela ratio burguesa que Camilo Prado confronta. Formar ateliês livres, propostas dos jovens artistas é propiciar a diferença. Mas a cidade os atomiza e expulsa para os arrabaldes e para casa. 
Claude Lantier queria conquistar Paris, se dirigia a Île de la Cité, ao coração da cidade para articular seu pensamento:

Un besoin de marcher encore, de s'abandoner à ce Paris, où les rencontres d'une seule journée lui emplissait le crâne, le fit errer jusqu"à la nuit, dans la boue glacée des rues, sous la clarté des becs de gaz, qui s'allumaient um à um, pareils à des étoiles fumeuses au fond du brouillard (ZOLA, 1974, p. 246).

Ele é tomado pela cidade: "ce coeur de Paris l'avait pris tout entier". Ela parece conter as possibilidades do novo "Quand il traversait Paris, il decouvrait des tableaux partout" (p. 261). Mas em ambos a cidade também se revela trágica: Logo no início, quando Claude encontra Christine, esta se refere à cidade como "la ville tragique" que vê "dans um éclaboussement de sang". Longe da cidade, no campo, Claude vive momentos alegres com o filho, a mulher e os amigos, mas não pinta. Paris e seu grupo de companheiros artistas ocupavam seu pensamento:

Paris le hantait, il y allait chaque moi, em revenait desolé, incapable de travail. arriva, puis I'hiver, um hiver humide, trempé de boue; et il le passa dans um engourdissement maussade, amer pour Sandoz lui-même, qui, marié d'octobre, ne pouvait plus faire si souvent le voyage de Bennecourt. Il ne semblait s'éveiller qu' a chacune de ses visites, il en gardait une excitation pendant une semaine, ne tarissait pas em paroles fiévreuses sur les nouvelles de là-bas (p. 221).

A cidade chama e deve ser conquistada, embora oponha uma resistência por vezes impossível de ser ultrapassada:

Rien n'existait que Paris, et encore, dans Paris, il n'existait qu'um horizon, la pointe de la Cité, cette vision que le hantait toujours et partout ce coin unique où il laissait son coeur (p. 371).

Camilo é insatisfeito com a cidade torta, o Rio anterior às reformas urbanas de 1904. A cidade não é acolhedora, mas violenta. No entanto aqui a verdadeira cidade a ser conquistada também é Paris, para onde vai o promissor pintor Agrário e que fica representada na francesinha que passa a viver com ele e por quem se apaixona Camilo. É ela que dá nome ao grupo de Zut!, interjeição francesa que repete. Há cenas poderosas no plein air do centro, em que se mostra a violência da cidade, sua resistência à transformação como uma cena em que um pintor fracassado pendura seu quadro num poste e a multidão investe contra ele.

L'oeuvre termina com o suicídio do pintor Claude Lantier e a arte nova se desenvolvendo nas telas de alguns que se apropriam de sua experimentação, desfazendo, no entanto, sua radicalidade. O romance brasileiro também tem um desfecho trágico e guarda certa ambigüidade. Termina com um hino à noite, em que o crítico Camilo Prado, caminhando pela cidade noturna, abandonado pelos amigos, escarra sangue, mas a lua, brilhando no escuro, sugere alguma transformação. 


\section{Referências}

BAUDELAIRE, Charles. As flores do mal. Trad. Ivan Junqueira. Rio de Janeiro: Nova Fronteira, 1985.

GONZAGA DUQUE, L. Mocidade Morta. 3. ed. Rio de Janeiro: Fundação Casa de Rui Barbosa, 1985.

KRAUSS, Rosalind. The originality of the avantgarde and other modernist myths. Cambridge, Massachussets; London, England: The MIT Press 1993.

SUZUKI, Márcio. O gênio romântico. São Paulo: Iluminuras, 1998.

ZOLA, Émile. L'oeuvre. Paris: Flamarion, 1974.

\section{Title}

Zola and Gonzaga Duque: the Artist and the City in the Turning of the Century

\section{Abstract}

The aim in the present essay is to make a comparative reading of the world of the arts and the city at the end of the nineteenth century and the beginning of the twentieth century as portraied in two novels, L'Oeuvre, by Émile Zola, and Mocidade Morta, by Gonzaga Duque, showing their proximities and specificities.

\section{Keywords}

Gonzaga Duque. Zola. Artist. City.

Recebido em 25.06.2011. Aprovado em 04.07.2011. 